\title{
PERANCANGAN ROBOT PEMINDAH BARANG BERBASIS LINE FOLLOWER
}

\author{
Sudimanto ${ }^{1}$ \\ Program Studi Informatika STMIK LIKMI \\ Email: sudianen@yahoo.com \\ Kevin ${ }^{1}$ \\ Program Studi Informatika STMIK LIKMI \\ Email: vinzrvt@gmail.com
}

\begin{abstract}
The development of technology for warehousing is more advanced, either is the process of moving goods that can be done automatically without intervention from people which make business processes more precise, fast and accurate. With the process that can run automatically make the process work more efficient, flexible and run continuously. Controlling and automation can be done easily, efficiently and quickly. Design goods moving robot is intended to facilitate the process of moving items especially in the warehouse section. The goods moving robot can move goods from the place of taking goods to the place of storage of goods in continuously and over and over again, so makes the process of moving goods can go on. The control of the goods moving robot is use Arduino UNO as the control center on the robot, as well as the LDR (Light Dependent Resistor) sensor which supports to checks on what is available. The motion system in the robot uses 1 motor driver, servo motor to raise and lower the Fork which is necessary to lift and unload goods and 2 DC motors that aim to move the robot from one place to another. The goods moving robot does the moving of goods which is in progress continuously taking the goods that are in the place of taking the goods and will stop if at the place of taking the goods are not related to the items to be moved. Robot that move too fast when turning can make unstable goods position so that can cause the goods fall from the fork.

Keyword: Robot, Warehouse, Arduino Uno, Fork, Motor
\end{abstract}

\begin{abstract}
ABSTRAK: Perkembangan teknologi dalam bidang pergudangan mengalami banyak kemajuan, salah satunya adalah proses pemindahan barang dapat berjalan secara otomatis tanpa adanya gangguan atau campur tangan manusia sehingga membuat proses bisnis menjadi lebih tepat, cepat dan akurat. Dengan adanya sebuah proses yang dapat berjalan secara otomatis dapat membuat proses yang ada di dalam pekerjaan menjadi lebih efisien, fleksibel dan berjalan terus menerus. Pengendalian dan ${ }^{2}$ otomatisasi dapat dilakukan dengan mudah, efisien dan cepat. Perancangan robot pemindahan barang bertujuan agar mempermudah proses pemindahan barang khususnya yang ada pada bagian pergudangan. Robot pemindah barang dapat memindahkan barang dari tempat pengambilan barang ke tempat penyimpanan barang secara terus menerus dan berulang, sehingga membuat proses pemindahan barang dapat berjalan terus. Pengontrolan robot pemindah barang ini menggunakan Arduino UNO sebagai pusat kendali pada robot, serta sensor LDR (Light Dependent Resistor) yang bertujuan untuk melakukan pemeriksaan terhadap muatan yang tersedia. Sistem gerak pada robot menggunakan 1 buah motor driver, motor servo untuk menaikan dan menurunkan Fork yang mana berfungsi untuk melakukan pengangkatan dan penurunan barang dan 2 buah motor DC yang bertujuan untuk menggerakan robot dari satu tempat ke tempat lainnya. Robot pemindah barang melakukan pemindahan barang secara terus menerus mengikuti ketersediaan barang yang ada di tempat pengambilan barang dan akan berhenti bila di tempat pengambilan barang tidak terdeteksi adanya barang yang akan dipindahkan. Robot yang bergerak terlalu cepat saat berbelok dapat membuat posisi muatan menjadi tidak stabil sehingga dapat membuat muatan terjatuh dari fork.

Kata kunci: Robot, Gudang, Arduino Uno, Fork, Motor
\end{abstract}

\section{PENDAHULUAN}

$\mathrm{K}^{\mathrm{c}}$ ebutuhan manusia akan pengunaan teknologi semakin berkembang, sehingga membuat teknologi makin berkembang sangat pesat dalam menyediakan kebutuhan-kebutuhan dasar yang sudah menjadi pokok dari teknologi itu sendiri seperti kecepatan, ketepatan, otomatisasi yang tidak berhenti mengganggu jalannya sebuah proses yang terkait langsung terhadap teknologi yang sedang digunakan. Perkembangan teknologi meliputi berbagai macam bidang, salah satunya meliputi bidang pergudangan. Robot Line Follower adalah teknologi dimana sebuah robot dapat mengikuti jalur arahan yang berguna sebagai penanda kemana robot harus berjalan. Garis arahan yang di gunakan dalam hal ini adalah garis yang memiliki warna lebih gelap dibanding dengan warna pada alasnya. Teknologi Robot Line Follower dapat diterapkan atau diimplementasikan ke dalam sebuah Forklift, dengan membuat jalur atau rute pemindahan menjadi pasti dan dapat bergerak secara otomatis mengikuti jalur atau rute sesuai arahan yang telah ditentukan.

Terdapatnya teknologi yang mampu memindahkan barang secara otomatis akan sangat membantu dalam berjalannya setiap proses yang berada di gudang. Membuat pelaksanaan dalam melakukan

\footnotetext{
${ }^{1}$ STMIK LIKMI, J1. Ir. H. Juanda No.96, Lebakgede, Kecamatan Coblong, Kota Bandung, Jawa Barat 40132
} 
pemindahan barang dapat dilakukan, dan berlangsung secara terus menerus, sekaligus meningkatkan kecepatan, akurasi dan proses bisnis pada gudang itu sendiri.

\section{DESKRIPSI KONSEP}

Robot pemindah barang otomatis merupakan sebuah kendaraan yang digunakan pada umumnya di dunia industri khususnya di bagian pergudangan. Selain di bagian pergudangan penerapan robot line follower dapat digunakan untuk memindahkan barang berdasarkan warna seperti yang dikutip dari jurnal TEKTRO yang ditulis oleh Aqsha Adella dengan judul rancang bangun robot mobile line follower pemindah minuman kaleng berbasis arduino yang berfungsi untuk melakukan penyortiran barang berdasarkan warna. Selain itu berdasarkan robot line follower dapat digunakan pengantar makanan seperti yang dikutip dari jurnal Teknik Elektro Universitas Sam Ratulangi yang ditulis oleh Janis dengan judul Rancang Bangung Robot Pengantar Makanan Line Follower. Dalam jurnal ini robot yang dirancang digunakan untuk mengantarkan makanan menuju 2 meja tujuan dengan mengikuti garis lintasan berwarna hitam. Pada penelitian ini robot dirancang agar dapat memindahkan sebuah barang secara otomatis dari satu tempat ke tempat lainnya. Dalam perancangan yang dibuat membutuhkan sebuah robot, tempat penyimpanan barang (Slot), dan tempat pengambilan barang (Pool). Robot berfungsi untuk melakukan pemindahan barang secara otomatis dari tempat pengambilan hingga tempat penyimpannya dengan berjalan sesuai dengan jalur yang telah dibuat. Slot berfungsi sebagai tempat penyimpanan barang yang nantinya akan memberikan informasi melalui sensor infra red kepada robot mengenai kondisi dari tempat penyimpanan yang nantinya akan digunakan sebagai tempat peletakan barang yang dibawa oleh robot. Sedangkan pool berfungsi sebagai tempat pengambilan barang awal, yang nantinya robot akan mendeteksi ada tidaknya sebuah barang/dus yang akan dipindahkan oleh robot. Robot dipasang sebuah sensor LDR dan sensor pengikut garis/line follower dengan lebar jalur sebesar $5 \mathrm{~cm}$ dengan warna hitam yang mana jalur ini berfungsi untuk jalannya robot agar dapat mengikuti garisgaris arahan yang telah ditentukan. Robot membaca jalur yang diberikan dengan mengunakan sensor line follower yang mana dari 5 buah sensor yang digunakan satu buah sensor untuk membaca jalur hitam disebelah sisi kiri dan tiga buah sensor yang di tengah sebagai pembaca jalur lurus sedangkan sisa satu buah sensor lainnya akan membaca sisi kanan dari robot. Letak pembacaan sensor dapat dilihat pada gambar 1.

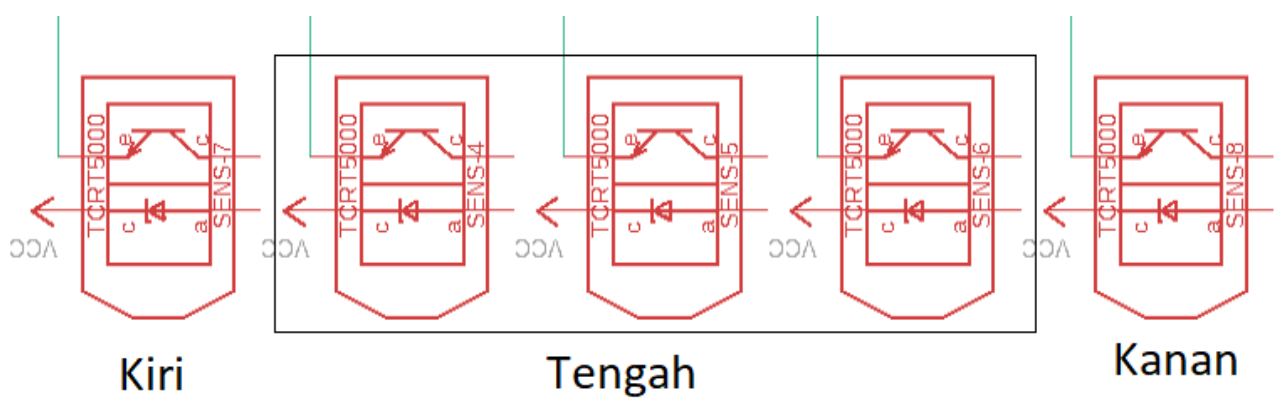

Gambar 1. Posisi Pembacaan Jalur pada sensor

Gambar 1 menunjukan bahwa dua buah sensor dibagian kiri digunakan untuk membaca apakah terdapat jalur sebelah kiri dan sebagai penanda bahwa robot berada pada tempat pengambilan barang. Serta digunakan sebagai penentu bahwa robot berbelok kiri. Sensor kanan digunakan untuk penentu bahwa terdapat belokan ke kanan sehingga robot dapat belok ke kanan. Jika hanya sensor tengah yang terdeteksi maka robot akan berjalan lurus hingga semua sensor mendeteksi jalur. Jika lima sensor mendeteksi jalur dan kondisi robot dalam keadaan mengangkut barang maka robot akan bergerak maju menuju ruang penyimpanan barang, setelah barang diturunkan robot akan berjalan mundur hingga menemukan jalur persimpangan 4 yang menandakan agar robot berjalan menuju tempat pengambilan barang. Dan jika robot tidak mengangkut barang maka robot akan berjalan mengikuti jalur.

Sistem gerak robot dari perancangan ini adalah mengunakan tiga buah roda yang mana dua buah roda digerakan dengan mengunakan motor DC dan sebuah roda bebas atau yang biasa disebut dengan ball caster. Fungsi dari ball caster hanya sebagai penahaan dari bagian depan robot dan menjaga robot agar tidak berat ke depan saat mengangkut barang. Posisi roda yang digunakan pada robot dapat dilihat pada Gambar 2. 


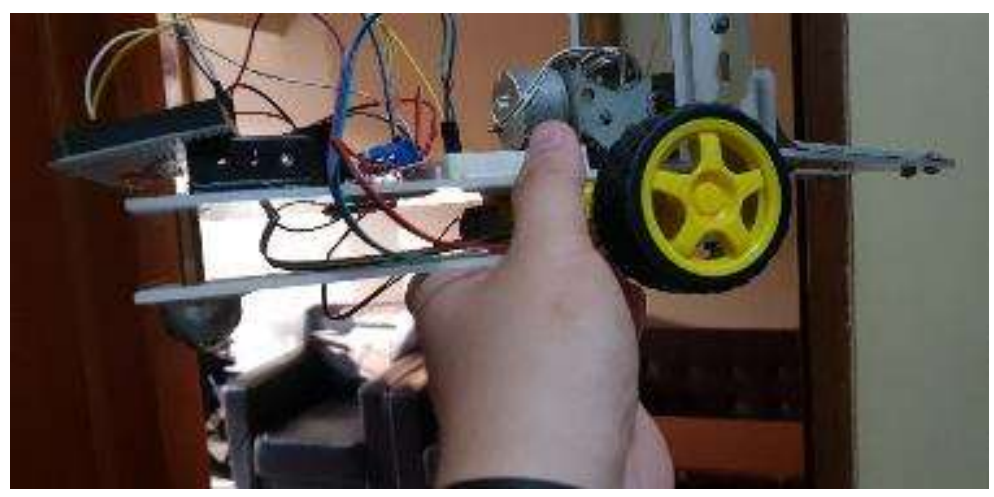

Gambar 2. Roda Pada Robot

Kondisi robot awalnya berada di tempat pengambilan barang dan robot dalam keadaan tidak membawa barang. Saat robot mendeteksi ketersediaan barang di tempat pengambilan barang, maka robot akan mengangkat barang tersebut menggunakan fork dan kemudian robot akan berjalan mengikuti garis atau jalur yang telah dibuat. Ketika robot sampai pada tempat penyimpanan barang, robot akan mendeteksi ketersediaan tempat kosong pada tempat penyimpanan tersebut. Jika kondisi tempat penyimpanan barang tidak terdapat tempat atau terisi penuh maka robot akan berjalan kembali mengikuti garis yang telah ditentukan dan akan terus berjalan hingga menemukan tempat penyimpanan yang kosong untuk meletakkan barang. Jika posisi robot di tempat pengambilan barang dan robot dalam keadaan mengangkut barang atau memiliki muatan pada fork, maka robot akan melewati tempat pengambilan barang tersebut dan akan berjalan mengikuti jalur guna mencari tempat penyimpanan yang kosong. Robot akan berhenti jika pada tempat pengambilan barang kosong dan robot tidak dalam keadaan memiliki muatan pada forknya. Bentuk rancangan robot dalam perancangan ini dapat dilihat pada Gambar 3.

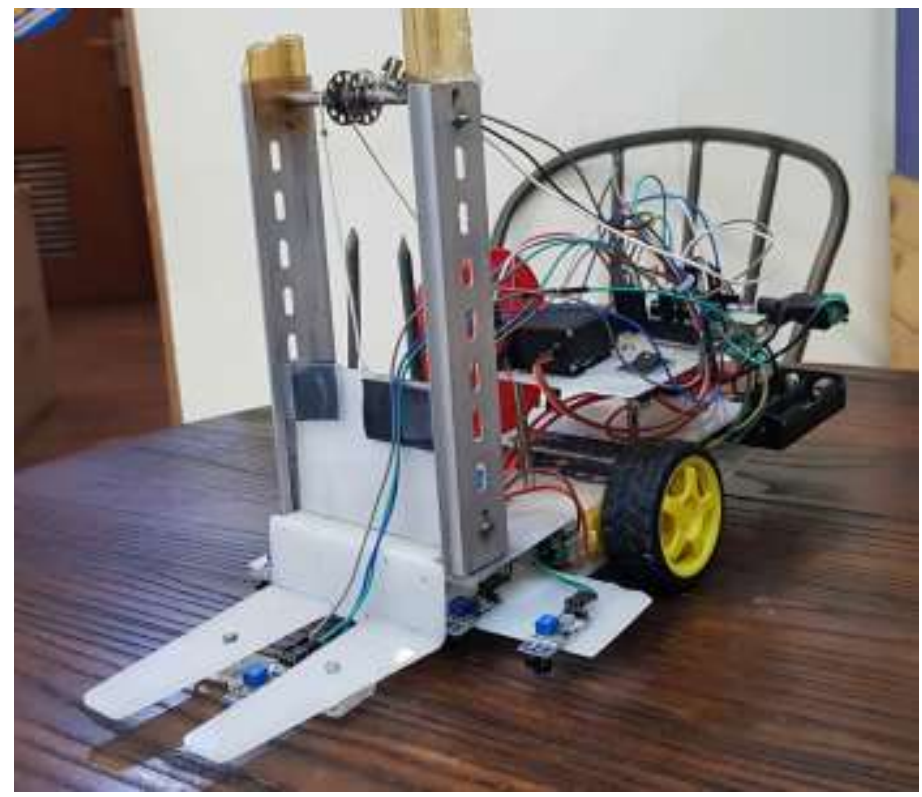

Gambar 3. Rancangan Keseluruhan Robot

Bagian depan robot disebut juga fork, diantara fork dipasang sebuah LDR guna mendeteksi apakah robot sedang dalam kondisi kosong atau dalam kondisi memiliki muatan. Informasi yang dikirimkan oleh LDR ke mikrokontroler untuk diproses untuk menentukan arah putaran dari motor servo yang berfungsi untuk mengangkat atau menurunkan fork. Bagian bawah robot dipasang sensor infrared yang berfungsi sebagai pembaca jalur. Dari sensor ini akan dibaca perbedaan intensitas yang diterima oleh penerima infrared yang kemudian diteruskan ke mikrokontroler guna untuk menentukan arah jalannya robot. 


\section{DIAGRAM BLOK RANCANGAN}

Berdasarkan deskripsi konsep yang telah dijabarkan, robot yang dirancang memiliki dua input. Input yang pertama ada sensor infrared yang berfungsi untuk membaca jalur yang telah ditentukan. Sedangkan input yang kedua ada LDR yang mana LDR ini berfungsi untuk mengindentifikasi apakah ada barang atau benda pada fork. Hasil dari pembacaan LDR akan diproses oleh mikrokontroler guna untuk menentukan arah putar dari motor servo. Diagram blok dari perancangan robot ini dapat dilihat pada Gambar 4.

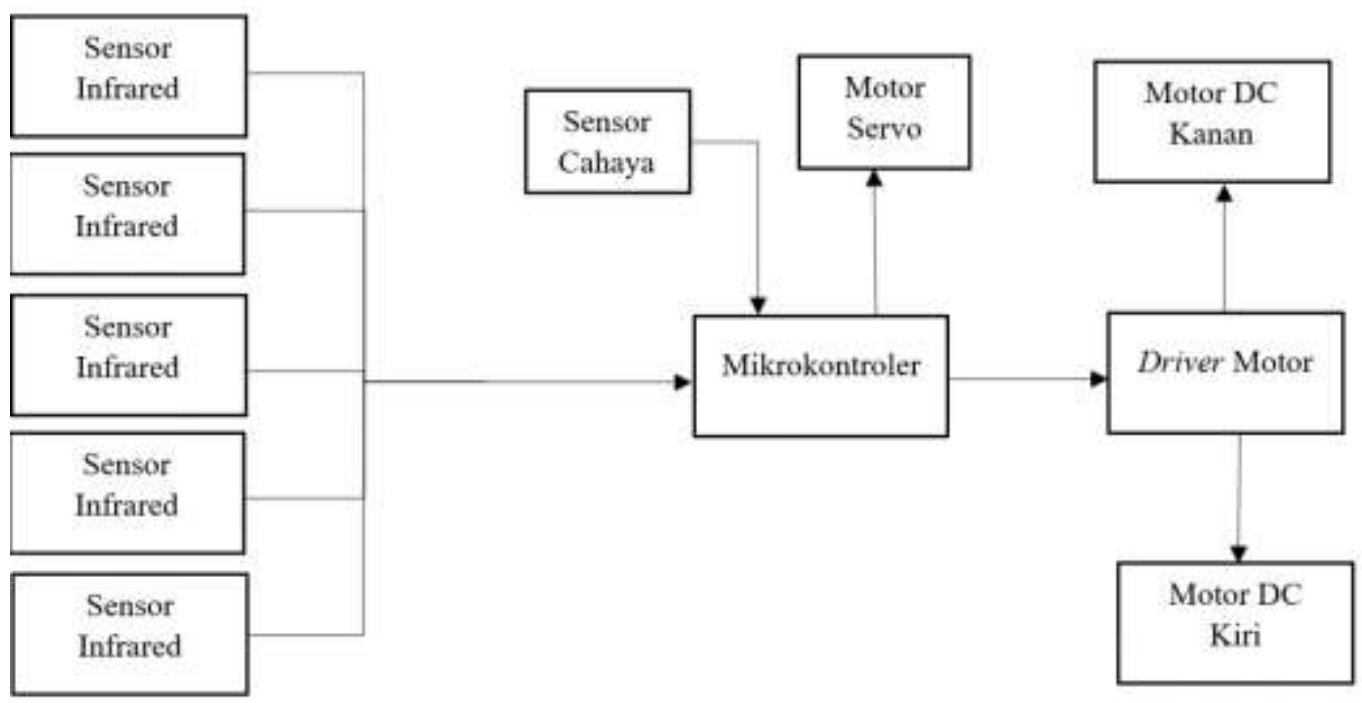

\section{Sensor Infrared}

Gambar 4. Blok Diagram Robot Pemindah Barang

Sensor infra merah (infrared) termasuk ke dalam kategori sensor biner, yakni sensor yang menghasilkan keluaran 0 atau 1. Sensor Infrared dapat digunakan untuk berbagai keperluan misalnya sebagai sensor pada robot line follower (Andrianto, 2013:89). Sensor infrared pada perancangan robot ini menggunakan tipe TCRT5000. Sensor infrared ini bersifat reflective. Sensor ini terintegrasi menjadi satu kesatuan antara pemancar infrared dan penerimanya. Sensor TCRT5000 menggunakan infrared sebagai pemancar dan menggunakan photodiode sebagai penerima.

Sensor TCRT5000 melakukan pendeteksian warna berdasarkan penyerapan warna dan intensitas pemantulan sinar infra merah yang dipancarkan oleh pemancar dan diterima oleh penerima. Dari perbedaan intensitas tersebut, maka digunakan sebagai bias pada basis foto transistor yang terkandung dalam sensor TCRT5000. Gambar sensor TCRT5000 dapat dilihat pada Gambar 5.

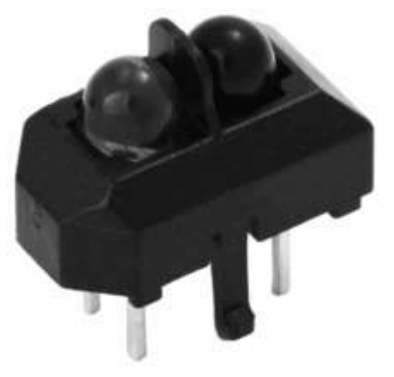

Gambar 5. Sensor TCRT5000

\section{Sensor Cahaya}

Sensor Cahaya Light Dependent Resistor (LDR) merupakan sebuah sensor yang digunakan dalam berbagai rangkaian elektronik. Light Dependent Resistor adalah sebuah sensor yang berfungsi untuk mengubah besaran cahaya menjadi besaran listrik. Sensor ini merupakan suatu jenis resistor yang peka terhadap suatu cahaya. Nilai resistansi yang diberikan sensor LDR akan berubah-ubah sesuai dengan intensitas cahaya yang diterima. Jika LDR tidak terkena cahaya maka nilai tahanan akan menjadi besar (sekitar $10 \mathrm{M} \Omega$ ) dan jika terkena cahaya maka nilai tahanan akan menjadi kecil (sekitar $1 \mathrm{k} \Omega$ ) [6]. Sensor LDR digunakan sebagai pemicu untuk menggerakkan fork pada robot serta sebagai indikator apakah 
robot dalam keaadan mengangkat barang atau dalam keadaan kosong. Sensor ini diletakkan diantara fork, jika pada fork terdapat benda/barang maka secara otomatis sensor LDR akan tertutup sehingga menaikkan resistansi pada LDR. Sehingga fork akan ditarik ke atas.

\section{Driver Motor DC}

Driver Motor berfungsi untuk membalikan polaritas tegangan yang berada pada motor, sehingga membuat pegerakan motor terbagi menjadi 2 arah yaitu, arah yang searah dengan jarum jam, dan arah yang berkebalikan dengan arah jarum jam. Ketika melakukan pengaturan terhadap perbedan tegangan daya motor dari $0 \mathrm{~V}$ sampai tegangan maksimum maka, dibutuhkan motor-controller atau driver motor. Modul motor ini memungkinkan mikrokontroler dapat menjalankan 2 Motor DC secara bersamaan maupun bergantian.

Driver Motor LN289N menggunakan IC yang merupakan jenis IC driver dan mampu untuk menghantarkan arus listrik pada masing-masing modul sebesar 2 Ampere. IC L298N terdiri dari transistor transistor logic (TTL) dengan menggunakan gerbang NAND yang berguna untuk memudahkan serta dapat menentukan putaran pada Motor DC. Driver motor mendapat suplai dari catu daya yang terdapat pada mikrokontroler yakni sebessar 4,8 V atau mendapat tegangan maksimal sebesar $35 \mathrm{~V}$ jika menggunakan catu daya eksternal. Driver motor pada perancangan ini menggunakan sebuah modul seperti yang ditunjukan pada Gambar 5.

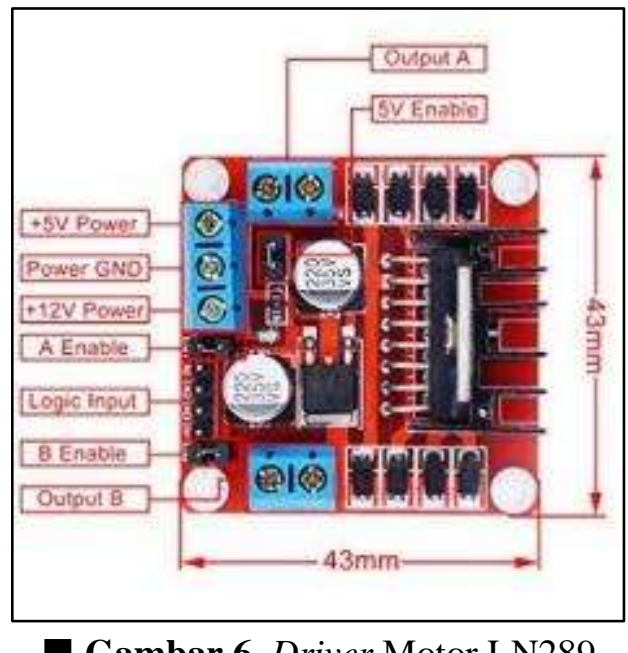

Gambar 6. Driver Motor LN289

\section{Motor DC}

Motor DC merupakan sebuah perangkat elektromagnetis yang mengubah energi listrik menjadi energi mekanik. Motor DC memerlukan suplai tegangan arus searah pada kumparan medan untuk diubah menjadi energi gerak mekanik. Energi mekanik ini biasanya digunakan untuk memutar blower dan digunakan juga pada sektor industri, dikarenakan tenaga motor DC sangat dibutuhkan khususnya pada sektor industri.

Motor DC merupakan sebuah aktuator yang banyak digunakan dalam mengembangkan aplikasi robotik. Pada perancangan ini motor DC yang digunakan berjumlah 2 buah yang mana digunakan sebagai pemutar roda, yang merupakan sistem gerak dari robot.

\section{Motor Servo}

Motor Servo adalah sebuah aktuator putar yang dirancang dengan sistem kontrol umpan balik tertutup. Motor servo dapat diatur untuk menentukan dan memastikan posisi sudut dari poros keluaran motor.. Penggunaan sistem kontrol tertutup pada Motor Servo berguna untuk mengontrol gerakan dan posisi akhir dari poros Motor Servo. Motor Servo sendiri biasanya digunakan dalam dunia industri, mobil mainan radio kontrol, robot, lengan robot, pesawat. Terdapat 2 jenis Motor Servo yang dibedakan berdasarkan rotasinya, yaitu Motor Servo dengan rotasi $180^{\circ}$ dan Motor Servo dengan rotasi continuous.

Motor Servo $180^{\circ}$ adalah jenis umum dari Motor Servo yang mana putaran poros keluarannya terbatas $\left(90^{\circ} \mathrm{ke}\right.$ arah kanan dan $90^{\circ} \mathrm{ke}$ arah kiri). Batas maksimum putaran yang dapat diberikan adalah $180^{\circ}$. Motor Servo dengan rotasi continuous adalah Motor Servo yang sama dengan jenis Motor Servo pada umumnya, namun perpuataran porosnya dalam dilakukan tanpa adanya batasan, dapat terus berputar ke kiri ataupun berputar ke kanan. Penggunaan motor servo pada perancangan ini untuk 
mengangkat dan menurun fork yang terdapat pada robot. Motor servo yang digunakan pada perancangan ini menggunakan motor servo tipe MG996R. bentuk fisik dari motor servo itu ditunjukkan pada Gambar 7.

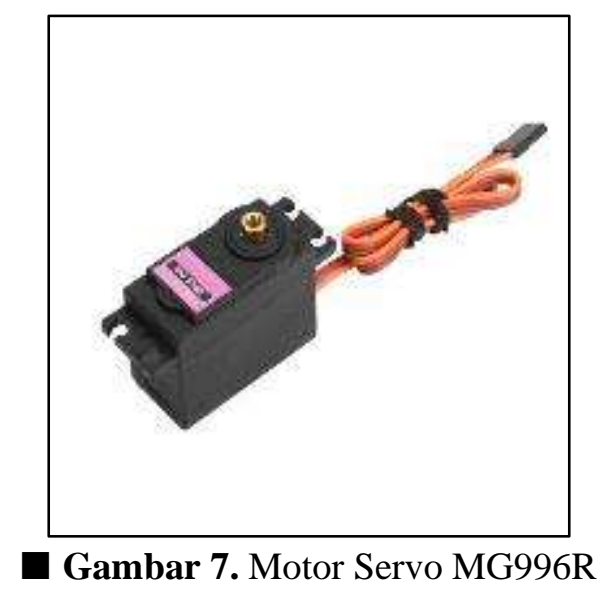

\section{Mikrokontroler}

Mikrokontroler merupakan sebuah microcomputer with few other application-spesific devices menurut [3]. Bentuk dari mikrokontroler ini merupakan sebuah IC yang mana berguna untuk menerima berbagai macam masukan (input), yang kemudian diproses dan memberikan hasil keluaran (output) sesuai dengan perintah yang tersimpan di dalamnya.

Perancangan robot ini menggunakan arduiono uno sebagai pusat pengendali dari robot. Arduino uno merupakan sebuah [4] tiny computer that you can program to process inputs and outputs between the device and external components you connect to it. Arduino uno adalah sebuah modul mikrokontroler yang berbasiskan pada ATMega328. Arduino Uno memiliki 14 pin masukan/keluaran yang mana 6 pin diantaranya dapat digunakan sebagai keluaran PWM (Pulse Width Modulation), 6 masukan pin analog, kristal osilator $16 \mathrm{MHz}$, koneksi USB, sambungan daya (jack power), kepala ICSP(In-Circuit Serial Programming), dan tombol reset. Dan pemograman untuk arduino menggunakan bahasa pemograman bahasa $\mathrm{C}$ yang disusun di dalam arduino IDE yang merupakan perangkat lunak untuk arduino itu sendiri.

\section{REALISASI KESELURUHAN SISTEM}

Realisasi dari perancangan ini adalah dengan menggabungkan seluruh modul menjadi satu kesatuan yang terintegrasi. Hasil akhir dari perancangan robot seperti Gambar 1 berbentuk seperti sebuah Forklift dengan menggunakan tiga buah roda, dua roda bersifat aktif dan satu roda sisanya adalah roda bebas atau roda pasif. Dua roda aktif memiliki penggerak yang bersumber dari motor DC dan gerakan dari motor DC tersebut dikendalikan oleh driver motor L298N. Sensor LDR yang dipasang pada fork dihubungkan secara langsung ke arduino sebagai masukan yang mengindikasikan kondisi fork pada robot. Jika kondisi fork dalam keadaan kosong maka secara otomatis LDR akan mengirimkan signal ke arduino. Signal yang dikirim oleh LDR akan diproses oleh arduino agar robot dapat berjalan ke tempat pengambilan barang.

Barang yang ada di tempat pengambilan barang akan dimasukan ke fork yang ada pada robot dan LDR akan terhalang oleh barang yang ada pada fork. Saat LDR terhalang oleh barang, arduino mulai mengontrol motor servo agar berputar sehingga dapat mengangkat fork yang berisi barang. Robot yang telah terisi barang akan mulai mencari jalur yang telah ditentukan melalui sensor infrared yang terpasang dibagian bawah robot. Sensor infrared yang terpasang dibagian bawah robot berjumlah 5 buah guna sebagai identifikasi jalur yang telah ditentukan. Robot berjalan sesuai sampai tempat penyimpanan barang yang kemudian membaca kondisi dari tempat penyimpanan tersebut apakah kondisi dalam keadaan kosong atau tidak. Jika kondisi penyimpanan dalam keadaan kosong maka robot akan meletakan barang sedangkan jika dalam keadaan terisi maka robot secara otomati akan berjalan melewati tempat tersebut dan mencari tempat penyimpanan yang kosong lainnya.

Sensor infrared dinotasikan dengan S sedangkan untuk angka menunjukkan posisi sensor tersebut. Pada flowchart terlihat bahwa jika sensor 1 sampai dengan sensor 3 mendeteksi jalur, maka menandakan bahwa tempat tersebut merupakan tempat pengambilan barang, sehingga robot akan mulai membaca apakah LDR terhalang benda/muatan, jika terhalang maka mikroontroler akan memerintahkan motor 
servo untuk berputar sehingga fork yang terisi barang tersebut dapat terangkat. Kemudian jika semua sensor infrared yang terpasang mendeteksi jalur maka robot akan berhenti untuk membaca data pada LDR apakah terhalang atau tidak. Jika terhalang maka robot akan maju ke tempat peyimpanan barang dan kemudian motor servo akan berputar untuk menurun fork pada robot. Jalur yang ditentukan untuk jalannya robot pemindah barang merupakan jalur searah, dengan kata lain robot tidak dapat berputar balik. Jalur searah ini dibuat agar tidak terjadi tabrakan antar robot pemindah barang. Diagram alir atau flowchart dari robot pemindah barang dapat dilihat pada Gambar 8 .

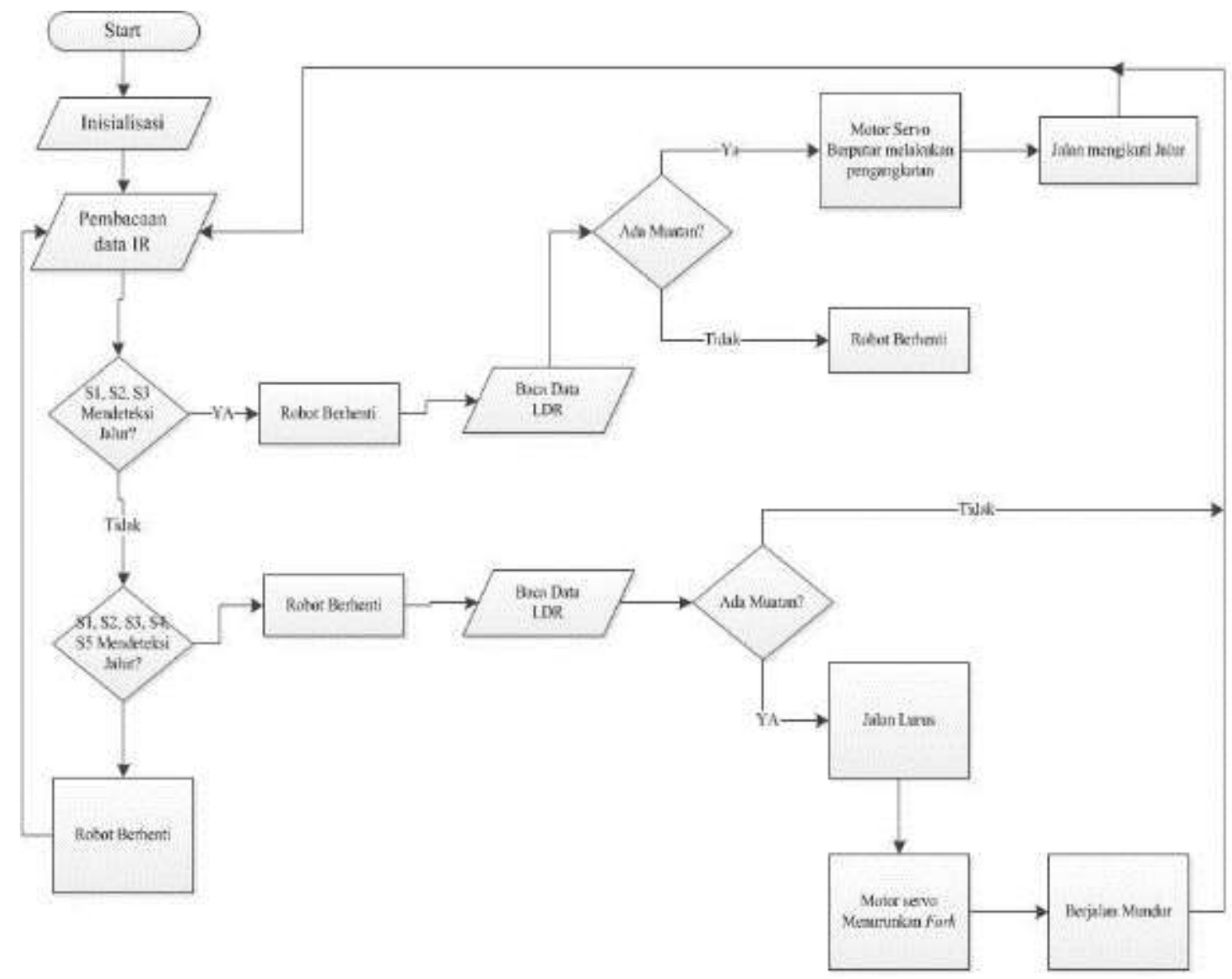

Gambar 8. Flowchart Robot

\section{PENGUJIAN DAN ANALISIS SISTEM}

Pengujian keseluruhan sistem dilakukan guna mengetahui apakah hasil rancangan dapat sesuai dengan tujuan dari perancangan atau tidak sesuai. Pengujian sistem dilakukan dengan menjadi beberapa bagian dari pengujian gerak robot, pengujian gerak motor servo, pengujian pembacaan sensor LDR, dan pengujian keseluruhan sistem. Pengujian keseluruhan sistem dibagi menjadi dua bagian yaitu pengujian pada saat melakukan penurunan dan peletakkan barang, bagian kedua dalam pengujian keseluruhan sistem adalah pengujian di tempat penyimpanan barang yang mana kondisi di tempat penyimpanan dalam kondisi semua tempat terisi dan kondisi kosong.

\section{Pengujian Motor DC dan Driver Motor}

Pengujian motor DC dan driver motor ini dilakukan guna mengetahui apakah motor DC dan driver motor terhubung dengan benar. Selain keterhubungan antar motor DC dan driver motor pengujian ini dilakukan untuk mengetahui jalan robot berdasarkan putaran roda. Robot dapat melakukan mundur, maju, belok kiri, belok kanan, belok $45^{\circ}$ ke kiri, belok $45^{\circ}$ ke kanan dengan membalikan arah arus, juga bisa memberhentikan salah satu roda demi kepentingan arah gerak robot. Hasil dari pengujian dapat dilihat pada Tabel 1 
Tabel 1 Pengujian Pergerakan Motor DC dan Uji Fungsi Motor Driver L298N

\begin{tabular}{ccccccc}
\hline EN_A & EN_B & IN1 & IN2 & IN3 & IN4 & Keterangan \\
\hline 1 & 1 & 0 & 1 & 1 & 0 & Maju \\
1 & 1 & 1 & 0 & 0 & 1 & Mundur \\
1 & 1 & 0 & 1 & 0 & 1 & Belok Kiri \\
\hline EN_A & EN_B & IN1 & IN2 & IN3 & IN4 & Keterangan \\
\hline 1 & 0 & 0 & 1 & 0 & 1 & Belok 45 Ke Kiri \\
1 & 1 & 1 & 0 & 1 & 0 & Belok Kanan \\
0 & 1 & 1 & 0 & 1 & 0 & Diam / Berhenti \\
0 & 0 & 0 & 0 & 0 & 0 & Diam / Berhenti \\
\hline
\end{tabular}

\section{Pengujian Motor Servo}

Pengujian Motor Servo bertujuan untuk mengetahui seberapa akurat Motor Servo dapat melakukan putaran sesuai dengan pemberian PWM yang dilakukan untuk mengendalikan pengangkatan, penurunan barang. Hasil pengujian yang dilakukan dapat dilihat pada Tabel 2 .

- Tabel 2 Pengukuran Putaran Pada Motor Servo

\begin{tabular}{ccc}
\hline Pemberian PWM Motor & Pembacaan Busur Derajat & Selisih \\
\hline $0^{\circ}$ & $0^{0}$ & $0^{0}$ \\
$30^{\circ}$ & $31^{\circ}$ & $1^{0}$ \\
$45^{\circ}$ & $49^{\circ}$ & $4^{0}$ \\
$60^{\circ}$ & $58^{\circ}$ & $2^{\circ}$ \\
$90^{\circ}$ & $90^{\circ}$ & $0^{\circ}$ \\
$135^{\circ}$ & $138^{\circ}$ & $3^{0}$ \\
\hline
\end{tabular}

Berdasarkan hasil pengujian yang ada pada Tabel 2 dapat disimpulkan bahwa pemberian PWM pada motor tidak memberikan putaran motor sesuai dengan pemberian PWM sehingga memiliki selisih antar pemberian PWM melalui program dengan hasil akhir dari putaran motor.

\section{Pengujian Sensor Cahaya LDR Pada Robot}

Pengujian Sensor LDR Robot bertujuan untuk mengetahui seberapa akurat sensor mendeteksi intensitas cahaya yang masuk ketika robot mendapatkan sebuah muatan atau robot tidak mendapatkan sebuah muatan. Intensitas cahaya yang dihasilkan adalah menggunakan satuan KOhm (Kilo Ohm). Pada pengujian ini, Intensitas cahaya yang dihasilkan oleh Sensor LDR Robot berkisar antara $300 \mathrm{KOhm}$ sampai $800 \mathrm{KOhm}$. Pada pengujian ini, jika Sensor LDR mendeteksi adanya sebuah muatan maka intensitas cahaya yang dihasilkan adalah sebesar $526 \mathrm{KOhm}$ sampai $750 \mathrm{KOhm}$, sebaliknya jika Sensor LDR mendeteksi tidak adanya sebuah muatan maka intensitas cahaya yang dihasilkan adalah sebesar $300 \mathrm{KOhm}$ sampai $525 \mathrm{KOhm}$. Pada Tabel 3 memberikan informasi mengenai jumlah / besaran cahaya intensitas yang masuk, dengan kondisi robot yang terdapat muatan ataupun tidak terdapat muatan. 
Tabel 3 Pengukuran Intensitas Cahaya Sensor LDR Pada Robot

\begin{tabular}{ccc}
\hline Sensor LDR Robot & $\begin{array}{c}\text { Output Intensitas Cahaya } \\
\text { Sensor LDR }(\text { KOhm })\end{array}$ & Keterangan \\
\hline Sensor LDR Mendeteksi Muatan \\
\begin{tabular}{c} 
Pada Robot \\
\cline { 2 - 3 }
\end{tabular} & $300-515$ & $\begin{array}{c}\text { Robot Mendeteksi Tidak } \\
\text { Terdapat Muatan }\end{array}$ \\
\cline { 2 - 3 } & $515-705$ & $\begin{array}{c}\text { Robot Mendeteksi Terdapat } \\
\text { Muatan }\end{array}$ \\
\hline
\end{tabular}

\section{Pengujian Sistem Robot Melakukan Penurunan dan Peletakan Barang}

Pengujian sistem robot saat melakukan penurunan dan peletakan bertujuan untuk melakukan penurunan dan peletakan barang di tempat penyimpanan barang dengan cara robot mendeteksi tempat penyimpanan barang menggunakan sensor pengikut garis (line follower). Hasil dari pengujian ini dapat dilihat pada Tabel 4. Pengujian ini menjelaskan bahwa dalam tiap tempat penyimpanan barang memiliki nilai yang bernilai 1 dan 0. Dalam nilai tersebut menjelaskan bahwa nilai 0 adalah kondisi tidak terdapat sebuah barang dan nilai 1 adalah kondisi terdapat sebuah barang. Pengujian yang dilakukan pada saat robot melakukan penurunan dan peletakan barang ini mengambil titik awal yang dimulai dari tempat pegambilan barang. Sehingga akan membuat robot berhenti di tempat pengambilan barang dan menunggu adanya muatan yang kemudian akan membuat robot berjalan ke tempat penyimpanan barang.

Hasil pengujian pada Tabel 4, menghasilkan presentase keberhasilan sebesar (80\%), dan mengalami kegagalan sebesar (20\%). Kegagalan terjadi dikarenakan ketika robot yang bergerak menyusuri lintasan garis menggunakan sensor pengikut garis, robot bergerak terlalu cepat ketika robot hendak berbelok, dan menukik terlalu tajam, sehingga membuat muatan pada robot tidak stabil (muatan maju / turun kedepan) bahkan terkadang membuat muatan pada robot terjatuh. Dengan adanya sebuah dorongan yang dihasilkan dari robot yang terlalu besar dan berdampak kepada muatan yang terlalu ringan sehingga memicu muatan yang ada pada robot bergerak maju kedepan, dan bahkan membuat muatan menjadi jatuh. Dalam pengujian tempat penyimpanan atau tempat untuk menurunkan barang di simbolkan dengan SL1, SL2, SL3.

- Tabel 4 Pengujian Sistem Robot Melakukan Penurunan Barang

\begin{tabular}{|c|c|c|c|c|c|c|c|c|}
\hline \multirow{2}{*}{ PERCOBAAN } & \multirow{2}{*}{$\begin{array}{l}\text { KONDISI } \\
\text { ROBOT } \\
\text { BERJALAN }\end{array}$} & \multicolumn{3}{|c|}{$\begin{array}{l}\text { KONDISI AWAL } \\
\text { SLOT }\end{array}$} & \multicolumn{3}{|c|}{ HASIL PENGUJIAN } & \multirow{2}{*}{ KESIMPULAI } \\
\hline & & SL1 & SL2 & SL3 & SL1 & SL2 & SL3 & \\
\hline 1 & $\begin{array}{c}\text { Membawa } \\
\text { Muatan } \\
\text { Menuju SL1 } \\
\text { Membawa }\end{array}$ & 0 & 0 & 0 & 1 & 0 & 0 & BERHASIL \\
\hline 2 & $\begin{array}{c}\text { Muatan } \\
\text { Menuju SL2 } \\
\text { Membawa }\end{array}$ & 1 & 0 & 0 & 1 & 0 & 0 & GAGAL \\
\hline 3 & $\begin{array}{c}\text { Muatan } \\
\text { Menuju SL2 } \\
\text { Membawa }\end{array}$ & 1 & 0 & 0 & 1 & 1 & 0 & BERHASIL \\
\hline 3 & $\begin{array}{c}\text { Muatan } \\
\text { Menuju SL3 } \\
\text { Tidak }\end{array}$ & 1 & 1 & 0 & 1 & 1 & 1 & BERHASIL \\
\hline 4 & $\begin{array}{l}\text { Membawa } \\
\text { Muatan }\end{array}$ & 1 & 1 & 1 & 1 & 1 & 1 & BERHASIL \\
\hline \multicolumn{8}{|c|}{ PRESENTASI KEBERHASILAN } & $80 \%$ \\
\hline \multicolumn{8}{|c|}{ PRESENTASI KEGAGALAN } & $20 \%$ \\
\hline
\end{tabular}

\section{Pengujian Sistem Jika Tempat Penyimpanan Terisi Semua}

Pengujian ini bertujuan untuk melakukan deteksi apabila seluruh tempat penyimpanan dalam kondisi penuh. Ketika robot berada di tempat penyimpanan barang dan tempat penyimpanan barang dalam kondisi penuh maka robot akan langsung bergerak lurus, meninggalkan tempat penyimpanan 
barang dan bergegas menuju ketempat pengambilan barang. Jika kondisi semua tempat penyimpanan barang dalam kondisi penuh dan robot dalam keadaan sedang mengangkut muatan maka robot akan berjalan sesuai dengan jalur yang telah ditentukan hingga mendapatkan tempat penyimpanan yang kosong.

Hasil dari pengujian ini dapat dilihat pada Tabel 5, dalam pengujian ini menjelaskan bahwa dalam setiap tempat penyimpanan dalam kondisi terisi semua dengan diberi nilai 1. Pengujian yang dilakukan pada saat robot sampai pada tempat penyimpanan dan kondisi tempat tersebut dalam keadaan penuh atau terisi sehingga membuat robot bergerak melewati tempat penyimpanan barang tersebut dan berjalan menuju ke tempat pengambilan barang.

- Tabel 5 Pengujian Sistem Jika Kondisi Tempat Penyimpanan Terpenuhi Semua

\begin{tabular}{|c|c|c|c|c|c|c|c|c|}
\hline \multirow{2}{*}{ PERCOBAAN } & \multirow{2}{*}{$\begin{array}{l}\text { STATUS } \\
\text { MUATAN } \\
\text { PADA } \\
\text { ROBOT }\end{array}$} & \multicolumn{3}{|c|}{$\begin{array}{l}\text { STATUS SLOT } \\
\text { KONDISI AWAL }\end{array}$} & \multicolumn{3}{|c|}{ HASIL PENGUJIAN } & \multirow{2}{*}{ KESIMPULAN } \\
\hline & & SL1 & SL2 & SL3 & SL1 & SL2 & SL3 & \\
\hline 1 & $\begin{array}{l}\text { Terdapat } \\
\text { Muatan }\end{array}$ & 1 & 1 & 1 & LEWAT & LEWAT & LEWAT & BERHASIL \\
\hline 2 & $\begin{array}{l}\text { Terdapat } \\
\text { Muatan }\end{array}$ & 1 & 1 & 1 & LEWAT & LEWAT & LEWAT & BERHASIL \\
\hline 3 & $\begin{array}{l}\text { Terdapat } \\
\text { Muatan }\end{array}$ & 1 & 1 & 1 & LEWAT & LEWAT & LEWAT & BERHASIL \\
\hline 4 & $\begin{array}{l}\text { Tidak Ada } \\
\text { Muatan }\end{array}$ & 1 & 1 & 1 & LEWAT & LEWAT & LEWAT & BERHASIL \\
\hline 5 & $\begin{array}{l}\text { Tidak Ada } \\
\text { Muatan }\end{array}$ & 1 & 1 & 1 & LEWAT & LEWAT & LEWAT & BERHASIL \\
\hline 6 & $\begin{array}{l}\text { Tidak Ada } \\
\text { Muatan }\end{array}$ & 1 & 1 & 1 & LEWAT & LEWAT & LEWAT & BERHASIL \\
\hline \multicolumn{8}{|c|}{ PRESENTASI KEBERHASILAN } & $100 \%$ \\
\hline \multicolumn{8}{|c|}{ PRESENTASI KEGAGALAN } & $0 \%$ \\
\hline
\end{tabular}

Gambar 9 merupakan pengujian pemindahan barang yang. Sedangkan pada Gambar 10 merupakan pengujian yang dilakuan secara keseluruhan sistem. Pada gambar 10 nomor 1 merupakan kondisi dimana lintasan dalam pengujian ini dalam keadaan kosong. Sedangkan pada nomor 2 kondisi dimana robot siap menerima barang berikutnya untuk dipindah ke slot kedua, dikarenakan slot 1 dalam keadaan penuh dan nomor 3 merupakan kondisi semua slot telah terisi dan robot berada pada di posisi awal.

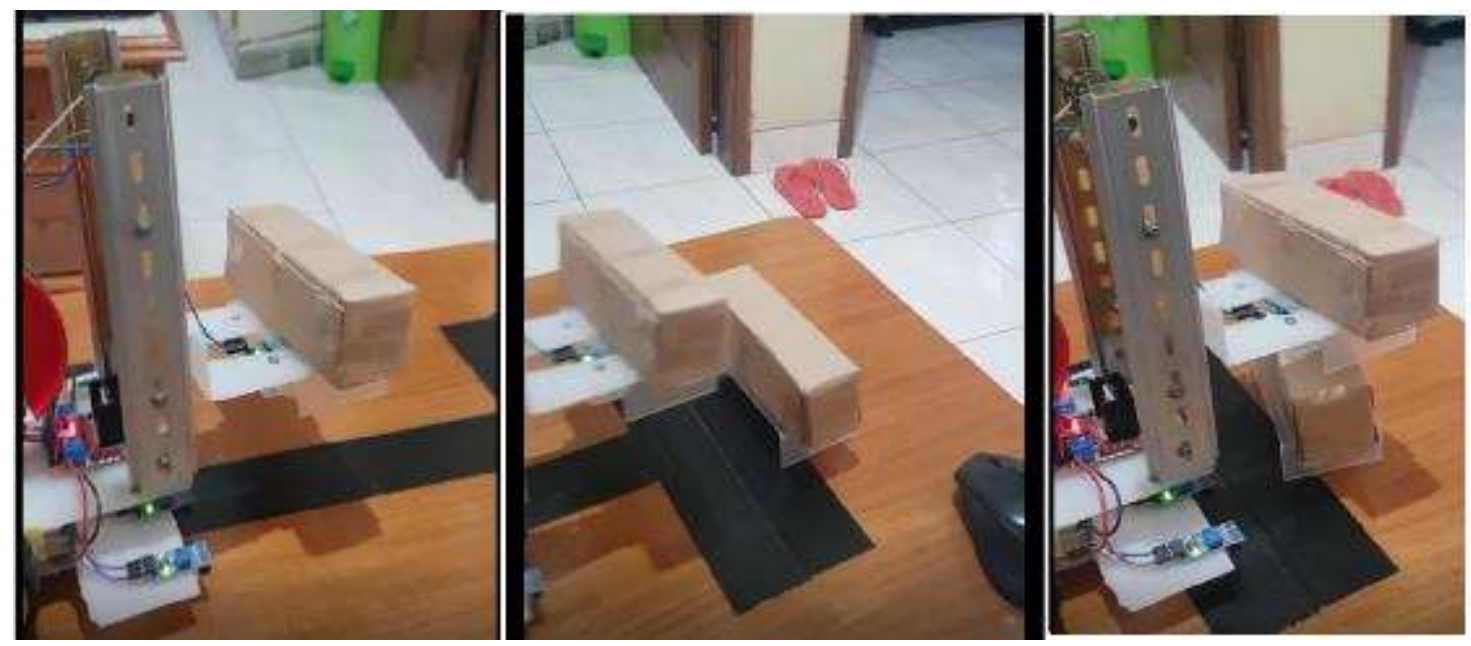

- Gambar 9. Pengujian Pengangkutan dan Peletakan Barang 


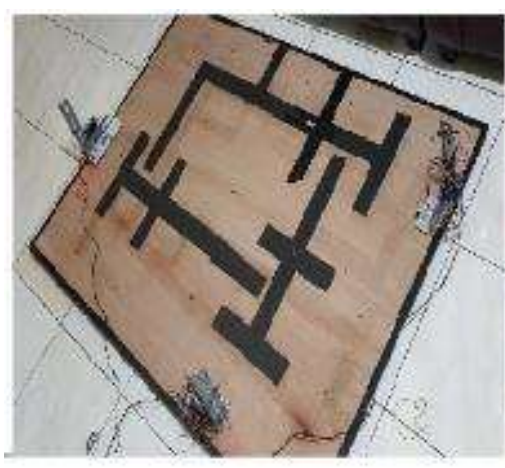

1

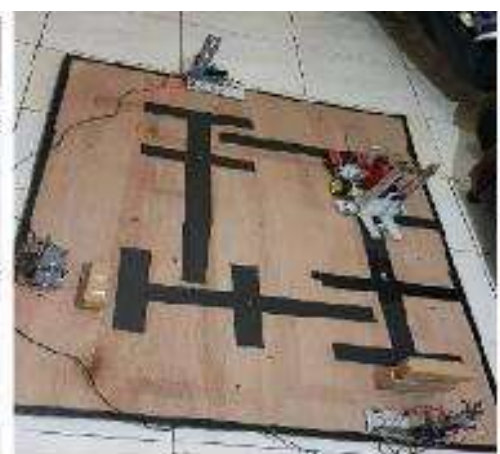

2

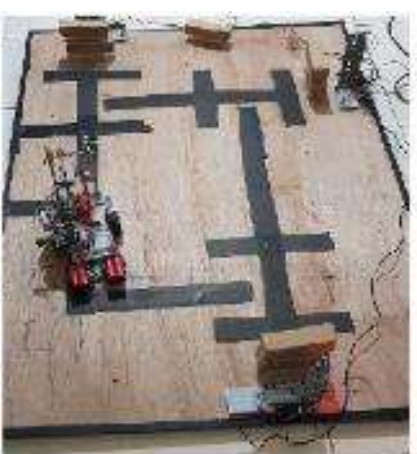

3

Gambar 10. Proses Jalannya Pemindahan Barang

\section{KESIMPULAN DAN SARAN}

Berdasarkan hasil dari pengujian keseluruhan sistem diperoleh kesimpulan bahwa robot pemindah barang dapat memindahkan barang secara terus menerus tanpa henti meskipun tempat penyimpanan barang telah terisi penuh. Ketika robot melakukan pemindahan barang, terkadang putaran awal motor yang diberikan terlalu besar dan mengakibatkan robot bergerak terlalu cepat, berbelok terlalu tajam yang membuat muatan pada robot menjadi tidak stabil, dan menyebabkan muatan menjadi bergerak maju kedepan yang mengakibatkan robot mendeteksi tidak adanya muatan pada fork, atau sering kali membuat muatan pada robot menjadi terjatuh.

Saran untuk pengembangan lanjut dari robot pemindah barang atau pengguna rancangan adalah

- Dengan menambahkan sensor warna sebagai penentu jalur jalannya robot

- Menambahkan informasi ketersediaan tempat untuk meletakkan barang di area penyimpanan barang

- Komunikasi antara tempat penyimpanan barang dengan robot menggunakan sebuah teknologi radio atau pun teknologi nirkabel.

\section{DAFTAR PUSTAKA}

[1] Adella, Aqsha, Kamal, Muhammad, Finawan Aidi. 2018. Rancang Bangun Robot Mobile Line Follower Pemindah Minuman Kaleng Berbasis Arduiono. Jurnal TEKTRO, Vol.2, No.2, September 2018

[2] Banzi, Massimo dan Michael Shiloh, 2014, "Getting Started with Arduino: The OpenSource Electronics PrototypingPlatform", Maker Media, Inc.

[3] Janis, Daisy A.N, Pang, David. S.T., MT, Wuwung, J. O. ST., MT. 2014. Rancang Bangun Robot Pengantar Makanan Line follower. Jurnal Teknik Elektro dan Komputer Vol.3, No.1, ISSN: 2301-8402

[4] ISO (8373:2012), 2012, "International Organization for Standardization", Robots and Robotic Devices.

[5] Kamal, Raj, Microcontrollers Architecture, Programming, Interfacing and System Design.: Dorling Kindersley Pvt. Ltd, 2009.

[6] McRoberts, Michael, 2010, "Beginning Arduino", Technology In Action.

[7] MG996R Robot Servo $180^{\circ}$ Rotation

Internet: http://www.towerpro.com.tw/product/mg995-robot-servo-180-rotation/ [2-April2019]

[8] Novianty Keyza, Lubis, tony. 2012. Perancangan Prototipe Sistem Penerangan Otomatis Ruangan Berjendela Berdasarkan Intensitas Cahaya. Seminar Nasional Teknologi Informasi 2012. Universitas Tarumanagara Fakultas Teknologi Informasi.

[9] Teori Motor DC dan Jenis-jenis motor DC

Internet: http://elektronika-dasar.web.id/teori-motor-dc-dan-jenis-jenis-motor-dc/ [4-Maret2019]

[10] Datasheet Vishay TCRT5000

[11] Datasheet ATMega 328. Atmel.

[12] Datasheet Sensor LDR (Light Dependent Resistor) SUNROM TECHNOLOGIES. 